Studies in African Linguistics

Volume 38, number 2, 2009

\title{
THE 'FORGOTTEN’ STRUCTURE OF IKALANGA RELATIVES
}

\author{
Rose Letsholo \\ University of Botswana
}

\begin{abstract}
Demuth and Harford (1999) contend that in Bantu relatives, the verb raises from $\mathrm{I}-\mathrm{C}$ if the relative morpheme is a bound morpheme while the subject remains in spec-IP resulting in subject - verb inversion. Ikalanga, a Bantu language spoken in Botswana has no subject verb inversion in relatives although the relative morpheme appears to be a bound morpheme. This observation challenges the conclusion reached in Demuth and Harford (1999). This raises the question, What then is the structure of the relative clause in languages like Ikalanga and Luganda? This paper argues that Ikalanga relative clauses differ from other Bantu relative clauses in that the projection that houses the relative feature (RelP) projects below TP while in Bantu languages where subject verb inversion is observed such as Shona it projects higher than TP. Thus, the variation in the structures of Bantu relative clauses can be accounted for if we understand that there is a parametric variation in the position in which RelP projects; lower than TP or higher than TP.
\end{abstract}

\section{Introduction}

Relativization in Bantu languages has been a topic of interest to linguists for some time. Among the many who have investigated this topic are Meeusen (1971), Bokamba (1976), Demuth (1995), Zwart (1997), Demuth and Harford (1999), Ngonyani (1999, 2001), Zeller (2004), Henderson (2006, 2007), and Simango (2007). Most of these works discuss the typology of Bantu relatives and have reached a consensus that there are at least three types of relatives found in Bantu languages. Henderson (2007) classifies the three types as follows:

Type 1: agreement with the subject and relativized NP

Type 2: agreement with the subject only

Type 3: agreement with relativized NP only 
Type 1 is illustrated by the Shona example below. In this example, the relative marker $d z a$ - agrees with the relativized NP mbatya while the verb agrees with the subject NP of the relative vakadzi.

$\begin{array}{llll}\text { mbatya } & \text { dza-va-kason-era } & \text { vakadzi } & \text { mwenga } \\ \text { clothes10 } & \text { RL10-SA2-sewed-APL1 } & \text { women2 } & \text { bride2 }\end{array}$

'clothes which the women sewed for the bride' (Demuth and Harford 1999)

Type 2 is exemplified by the Swati example. The relative marker agrees with the subject NP tintfombi but not with the relativized NP umfati.
umfati
tintfombi
leti-m-elekelela-ko
woman 1
girl10
RC10-OC1-help-RS

'the woman whom the girls help' ( Zeller, 2004: Ex 22)

Type 3 relative is exemplified by Dzamba in example (3).

$\begin{array}{lll}\text { imundondo } & \text { mú-kpa-aki } & \text { omoto } \\ \text { jug5 } & \text { AGR5.REL-took-IMP } & \text { person }\end{array}$

'the jug which the person took' (Bokamba 1976)

In Type 3 relative clauses, there is no segment which is classifiable as a relative marker. Rather, relativization is achieved through the supra-segmental feature of high tone on the verb. The agreement observed on the verb is triggered by the relativized NP and not the subject this time. The subject NP is post verbal as in Type 1 relatives.

Clearly the categorization above leaves out languages such as Ikalanga and Luganda which have a different strategy for forming object relatives than all three types of languages discussed above ${ }^{2}$. Consider example (4) from Ikalanga and example (5) from Luganda.

\footnotetext{
${ }^{1}$ See list of abbreviations at the end of the article.

${ }^{2}$ In fact, Demuth and Harford (1999) discuss this structure in a footnote noting that this particular method of forming relative clauses is marked in Shona.

(i) mbatya vakadzi dza- va-kasonera mwenga clothes $_{10} \quad$ women $_{2} \quad \mathrm{REL}_{10}-\mathrm{SA}_{2}$-sewed for 1 bride 'clothes which the women sewed for the bride'( Demuth \& Harford, 1999 Ex (i))
} 
(4) ngumbá Lúdo ya-á-ká-báka

house9 Ludo1a RELAgr9-SA1-past-build

'the house that Ludo built'

(5)

$$
\begin{array}{llll}
\text { emikeeka } & \text { abawala } & \text { gye-ba-a-luka } & \text { te-gi-gasa } \\
\text { mat4 } & \text { girl2 } & \text { RELAgr4-SA2-past-plait neg-4-be.of.use }
\end{array}
$$

'The mats the girls plaited are unsuitable (Ashton et al. 1954:144)

Notice that in examples (4) and (5) the relative marker is a subminimal prosodic unit which attaches to the verb and that there is no subject verb inversion in both of these examples. This is contra the characterization made in Demuth and Harford where it is claimed that if the relative marker is a subminimal prosodic unit the verb raises to $\mathrm{C}$ and the subject is left in spec IP and that this results in subject verb inversion. In addition, examples (4) and (5) do not fit in the typology of Bantu relatives posited by Henderson (2007). For example, while they are similar to Henderson's Type 1 relatives in that the relative marker agrees with the relativized NP and is a subminimal prosodic unit which attaches to the verb, they differ from Type 1 relatives in that Ikalanga and Luganda have no subject verb inversion. Ikalanga and Luganda are similar to Type 2 relatives in that the relativized NP and the subject NP linearly follow one another in that order. However, they are different from Type 2 in that the SA in Type 2 relatives precedes the OM while in Ikalanga and Luganda there is no OM; instead there is a relative marker which linearly precedes the SA. In relation to Type 3, Ikalanga and Luganda can be said to be similar to these relatives in that, at least in Ikalanga, relativization is partly achieved through the use of a supra-segmental feature, namely low tone on the morpheme that agrees with the relativized NP (i.e. the relative marker). They are different from Type 3 in that in both Ikalanga and Luganda there is no subject verb inversion.

The data from the different Bantu languages described above suggests that the position of the relative marker may differ from one Bantu language to another (see section 6 for a further discussion of this point). Table 1 below summarizes characteristics of direct relatives of the Bantu languages discussed in this paper. 
Table 4 Summary of characteristics of direct relative clauses in some Bantu languages

\begin{tabular}{|c|c|c|c|c|c|c|}
\hline Language & $\begin{array}{l}\text { S-V } \\
\text { inversion }\end{array}$ & $\begin{array}{l}\text { Relative } \\
\text { Pronoun }\end{array}$ & $\begin{array}{l}\text { Relative } \\
\text { precedes } \\
\text { SA }\end{array}$ & $\begin{array}{l}\text { Relative } \\
\text { clitic }\end{array}$ & $\begin{array}{l}\text { Rel agrees } \\
\text { with } \\
\text { relativized } \\
\text { NP }\end{array}$ & Tone \\
\hline Ikalanga & $X$ & $X$ & $\checkmark$ & $\checkmark$ & $\checkmark$ & $\checkmark$ \\
\hline Luganda & $X$ & $X$ & $\checkmark$ & $\checkmark$ & $\checkmark$ & $?$ \\
\hline $\begin{array}{l}\text { Shona } \\
\text { (marked) } \\
\text { Shona } \\
\text { (unmarked) }\end{array}$ & $\begin{array}{l}X \\
\checkmark\end{array}$ & $\begin{array}{l}X \\
X\end{array}$ & $\begin{array}{l}\checkmark \\
X\end{array}$ & $\begin{array}{l}\checkmark \\
\checkmark\end{array}$ & $\begin{array}{l}\checkmark \\
\checkmark\end{array}$ & $\begin{array}{l}\checkmark \\
\checkmark\end{array}$ \\
\hline Swati & $X$ & $X$ & $\mathrm{X}$ & $\checkmark$ & $\mathrm{X}$ & $?$ \\
\hline Dzamba & $\checkmark$ & $X$ & $\mathrm{X}$ & $X$ & $\checkmark$ & $\checkmark$ \\
\hline Sotho & $\mathrm{X}$ & $\checkmark$ & $\checkmark$ & $X$ & $\checkmark$ & $\mathrm{X}$ \\
\hline
\end{tabular}

Given the scenario described above, three questions arise, namely:

1. What is the syntactic position of the relative marker in Ikalanga?

2. What is the structure of the Ikalanga relative clause?

3. How can we account for the difference between the Ikalanga/Luganda relative clause (which has no subject verb inversion) and the relatives of other Bantu languages, such as Shona, which have subject verb inversion?

\section{Background}

Ikalanga is usually described as one of the six dialects in the Shona cluster of languages. The following is a list of Shona dialects: Karanga, Zezuru, Korekore, Manyika, Ndau, and Ikalanga. Shona is the major language group of Zimbabwe, one of Botswana's neighbors. Guthrie (1967-71, v. 4) classifies Ikalanga as an S.16 language. Area S includes other southern Bantu languages such as Setswana, Sotho, Zulu, Xhosa, Venda \& Tsonga. In Botswana, Ikalanga is spoken in the north eastern and central parts of the country. It is estimated that there are 150, 000 speakers in Botswana although there are probably many more by now (Mathangwane, 1999). Speakers of the language are collectively referred to as Ba-kalanga (class 2), while a single speaker is referred to as N-kalanga (noun class 1).

Ikalanga is a tone language. There are two tones in the language, namely, high and low. These tones can bring about a lexical semantic distinction as 
illustrated in example (6) and they can bring about a grammatical distinction as shown in example (7).

(6) a. mbilá 'thin porridge fed to babies'

b. mbíla 'rock rabbit'
a. ngwanáná wá-ka-ízela ${ }^{3}$
girl1 SA1-prg-sleep
'The girl is sleeping.'
b. ngwanáná waká-ízela girl1 Rel. AGR1-sleep 'the girl who is sleeping.'

Examples (6a) and (6b) are minimal pairs whose semantic distinction is brought about by the differential placement of tone. Similarly examples (7a) and (7b) are grammatically distinctive with (7a) being a declarative and (7b) being a subject relative clause. Again, the distinction between the pair is brought about by the placement of high tone on the subject marker in (7a) with the relative marker in $(7 b)$ having a low tone. These examples follow the general Bantu pattern of distinguishing subject relatives from declaratives through tone marking.

Secondly, agreement plays an important role in the grammar of this language. For example, the class of a noun used in a sentence, clause or phrase determines the morphological shape of the agreement on either the verb or the adjective describing a noun (see Letsholo 2004 for a detailed discussion of this). The examples in (8) illustrate.
a. chibúlúlú chá-ka- ízéla lizard7 SA7- past-sleep
'The lizard is sleeping.'

\footnotetext{
${ }^{3}$ The morpheme 'ka-' in Ikalanga is a portmanteau morpheme: it can be used to express the present progressive e.g. in example (7a), as part of the relative agreement marker e.g. in (7b) or as a past tense marker as in the sentence :

ii) Ludo wa-ka-bika madekwe. Ludo $_{1 a} \quad \mathrm{SA}_{1}$-past-cook yesterday Ludo cooked yesterday.
} 


\section{b. n-lúmé n-lefú \\ man1 AGR1-tall \\ 'the man who is tall'}

In example (8a) the noun chibúlúlú which belongs to class 7 selects the agreement morpheme $c h$ - which attaches to the verb and its other extensions. Similarly, in example (8b), the noun n-lúmé, which belongs to class 1 , selects class 1 agreement morphology, which is prefixed to the adjective -lefu to describe the man.

Like other Bantu languages, e.g. Kilega (Kinyalolo 1991) and Kindendeule (Ngonyani 1999), Ikalanga has no independent relative pronoun, that is, it does not have the kinds of relative pronouns that one finds in languages like English, which occur independently of the verb. Rather, Ikalanga has a relative marker, an element which has no independent status as it forms part of the verbal morphology and is distinguished from SAs by its low tone. However, WH words do exist in the language. For example, ani $=$ who, $n i=$ what, $p i=$ which, ngayi $=$ where, chini $=$ how/how come. In addition, Ikalanga has no articles equivalent to 'a/an' or 'the' in English. Further, Ikalanga is a discourseconfigurational language. These kinds of languages display flexibility because they use topic and focus strategies, which result in the placement of NPs in different positions such as those observed in the examples in (9) (see Bresnan and Mchombo 1987 for a discussion of topic and focus constructions in Bantu and Kiss 1995, Jelinek 1984, for a full discussion of the features of discourse configurational languages).

a. ludó wá-ka-téngá lóri. ludo1a SA1-past-buy car9 'Ludo bought a car.'

b. wá-ká-téngá lóri Ludó SA1-past-buy car9 Ludo1a 'She bought a car, Ludo.

c. Lórí wá-ká-í-ténga Ludó Car9 SA1-past-OM9 - buy Ludo1a 'The car, Ludo bought it.'

In example (9a) the subject NP Ludo is in its canonical position. In (9b) the subject NP is dislocated to the right, and in (9c) the object NP lori is topicalized. 
Before any further discussion of the Ikalanga data is discussed, I outline the theoretical assumptions underpinning the analysis in the next sub-section.

\section{Theoretical assumptions}

I follow the Minimalist theoretical framework proposed in Chomsky (2000) in which syntactic operations such as movement are driven by features attracting others which have similar properties as them. Formally speaking, "attract" is a syntactic operation in which a category $\beta$ is displaced from its base position because another category $\alpha$ has matching features with it. $\beta$ has un-interpretable features and therefore $\alpha$ attracts $\beta$ to check these un-interpretable features. This operation results in displacement of $\beta$ from its original position $A$ to a new position B. Displacement is constrained by universal principles of grammar, in this case the Phase Impenetrability Condition (PIC). PIC is an economy principle that requires that in order to overcome computational complexity, a derivation proceeds strictly by phases. The Complementizer Phrase (CP) and the Verb Phrase $(v \mathrm{P})$ are considered to be strong phases, that is, phases whose edges can attract other elements. The Complementizer Phrase is the highest level grammatical construction at which operations such as WH movement take place. The CP domain is also commonly referred to as the left periphery in the literature. The next highest level after CP is the Inflectional Phrase (IP). IP is the equivalent to the Sentence (S) in earlier versions of Government and Binding Theory.

3.1 The syntactic position of the relative marker. There is controversy regarding the status of relative markers in Bantu languages. While Meeusen (1971) and Kinyalolo (1991) maintain that the relative marker is not a relative pronoun but rather an agreement morpheme which agrees with an abstract relative pronoun, Ngonyani (1999), Harford and Demuth (1999), and Demuth (1995) contend that the relative marker is a head which occurs in the left periphery, specifically the head of CP. My position is similar to Kinyalolo (1991) in seeing that the relative marker is not itself a relative pronoun but an agreement marker agreeing with a phonologically null relative pronoun. The fact that the relative pronoun is null in Bantu languages such as Ikalanga is consistent with the fact that these languages have null articles.

In this paper, I argue that the relative marker is a subminimal prosodic unit which comes into the lexicon as part of the verb in relative clause constructions, but that since it is on this morpheme that the low tone of relativization is marked or assigned, the checking of this relativization feature must occur in a projection higher than IP, otherwise there is no way of 
distinguishing between relatives and declaratives such as (7a) and (7b) above, if both the relative feature and the SA features are checked in the same domain . The question now becomes, if the relative marker comes into the lexicon as part of the verb as alluded to above, is there any evidence to support the idea that the verb moves out of VP in Ikalanga? I address this question next.

3.2 Relatives and adverbs in Ikalanga. As illustrated in ex (10) below, relatives in Ikalanga can be modified by adverbs:
a. Néo
wá-ka-bíka
shadza
zubuyanána
Neola SA1- past-cook
porridge
well
'Neo cooked porridge well.'
b. * Néo zubuyanána
wá-ka-bíka
SA1.past.cook
shádza Neola well 'Neo cooked porridge well.'
porridge
c. *Zubuyanána Well 'Neo cooked porridge well.'
wá-ka-bíka
shádza
porridge

Sentence (10a) is a grammatical structure because the verb has moved to a position higher than the adverb zubuyanana, which we assume is adjoined to VP. I assume that the position that the verb moves to is within IP. Example (10b) is ungrammatical because the verb has not moved out of VP while (10c) is ungrammatical because the adverb is adjoined either to IP or to a position higher than IP. Further evidence that the verb moves from VP to Infl comes from the fact that the verb is always adjacent to Infl categories, namely, the tense marker and the subject agreement marker, and no element is allowed to intervene between the verb and these categories. Consider the examples below:
a. *Néo
wá-ka- zubuyanána bík
Neola
SA1 - past-well-cook
shádza
porridge
'Neo cooked porridge well.'
b. *Néo wá- zubuyanána-ká-bíka shadza Neola SA1 -well-past-cook porridge
'Neo cooked porridge well.'


Based on the evidence above, I conclude that the verb in Ikalanga moves out of VP to an Infl position. In section 5 I discuss adverb placement in relation to the position of the relative marker. Next, I investigate whether relativization in Ikalanga is a left periphery phenomenon.

\subsection{Left periphery characteristics of Ikalanga relatives}

3.3.1 Co-occurrence with conditionals. The relative marker is mutually exclusive with other elements that occur in the $\mathrm{C}$ domain, e.g., conditionals (see Letsholo 2002 for detailed discussion, and Ngonyani 1999 for a discussion of similar phenomena in KiSwahili).
a. Lori a-yá-ka zhá,
car9 cond-SA9-arrive
Néo
ú-noo-í-ténga
car9 cond-SA9-arrive Neola SA1a-will-OM-buy
'If the car has arrived, Neo will buy it'.
b. *Lori a -ya-ká-zhá, Néo ú-noo-íténga.
car9 cond-RelAgr9-arrive Neo1a Neg.SA1-will.-OM-buy
'If the car has arrived, Neo will buy it'.

(12b) is ungrammatical under the reading in which $y a$ is a relative marker, but grammatical if $y a$ is a subject marker as in (12a). The ungrammaticality of (12b) suggests that the relative marker cannot co-occur with the conditional. This might mean that they compete for the same syntactic slot.

3.3.2 Evidence of A-bar movement-island constraint violation. Chomsky (1977) discusses tests that have come to be considered as classic diagnostic tests for A-bar movement. Some of these include the fact that A-bar movement allows movement across an intervening noun phrase, allows cyclic cross-clausal movement and obeys island constraints. In the examples that follow, I apply these tests to the Ikalanga data to show that these data suggest that Ikalanga relatives undergo A-bar movement. I begin with the lack of relativized minimality effect in example (13).
isípá ${ }_{\mathrm{i}} O p_{\mathrm{i}}$ Néo
cha-á-ká-pá
Nchídzi $t_{i}$
soap7 Neo1a
Rel.AGR7-SA1-past-give Nchidzila
'the soap that Neo gave Nchidzi'

In example (14), the operator moves across the NP Nchidzi in order to get to the position before the subject NP Neo and this sentence is grammatical, suggesting that no relativized minimality effect (Rizzi, 1990) is incurred in the 
course of the operator movement. This kind of result is associated with A-bar movement. Next, consider example (14), an example of an island constraint violation.

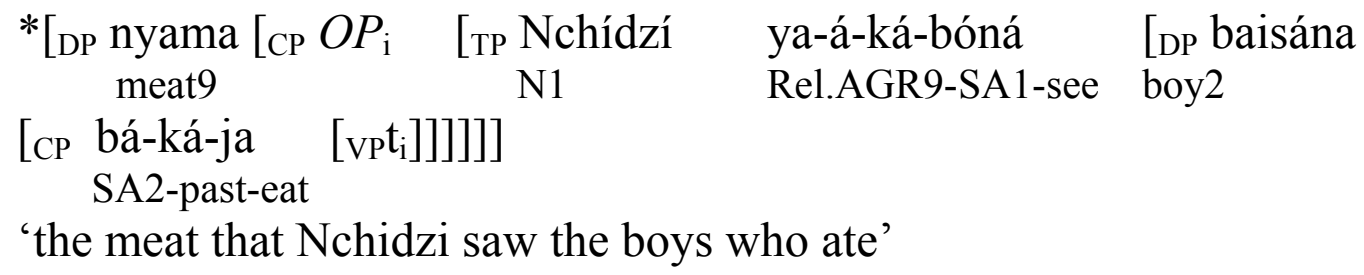

Example (14) is ungrammatical because the operator skips over spec CP of the embedded clause since it is occupied by the null relative pronoun. Skipping over a CP constitutes violating an island constraint or, in Minimalist terms, violating the Phase Impenetrability Condition (PIC). The fact that (14) is ungrammatical is consistent with the fact that a universal principle of grammar has been violated. Now consider example (15). Example (15) illustrates that relatives allow cyclic cross clausal movement.

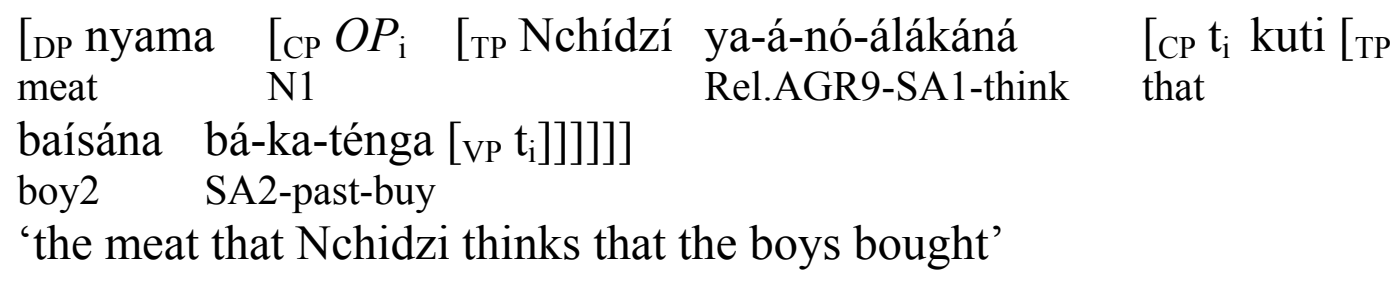

Example (15) is grammatical because the movement of the operator from the embedded clause to the matrix clause is cyclic, that is, the operator lands in intervening empty spec CP positions consonant with PIC. In the example above, spec $\mathrm{CP}$ of the embedded clause is unoccupied and therefore the operator lands here before moving further to the matrix clause.

3.3.3 Tone Marking. Consider the examples in (16):
a. nlúmé wa-ká-ízela man1 Rel.AGR1-asp-sleep
'the man who is sleeping'
b. nlúmé wá-ka-ízela. man1 SA1-asp-sleep 'The man is sleeping.'


The only thing that marks (16a) as a relative clause as opposed to the declarative clause in $(16 \mathrm{~b})$ is that the relative marker has a low tone while the subject agreement marker has a high tone. This means that low tone, an important sign of relativization in Ikalanga, is a feature of the left periphery and therefore a verb which carries a relative marker needs to raise to the left periphery where this feature is checked. If this relative feature is not checked, then the resulting sentence will just be another declarative sentence (16b), or if it is a sentence involving object relativization, then an anomalous sentence would result ( (17) below). Example (17) is anomalous because a relative agreement morpheme cannot take a high tone such as that of the subject marker or a neutral tone.

$$
\begin{array}{lll}
\text { *lori } & \text { yá -á-ká-ténga } & \text { yá-ka-míla. } \\
\text { car9 } & \text { Rel.AGR9-SA1-asp.-buy } & \text { SA9-past-lost }
\end{array}
$$

'The car which he bought is lost.'

3.3.4 Summary. The fact that other elements that occur in the left periphery can occur in the same position occupied by the relative marker suggests that this element occurs in the left periphery. I therefore conclude that the relative marker is an agreement morpheme that is hosted by the verb, the combination of which raises to some projection within the left periphery to check the relative feature of the relative marker.

\section{The structure of relatives}

In this section I discuss several alternative analyses, all of them following Chomsky's (1977) analysis of relative clauses. In this analysis, the verb selects an operator as a complement. The operator is co-indexed with the head noun of the relative clause. To check the $\mathrm{WH}$ feature, the operator moves from the complement position of the verb (in relativized objects) to spec. $\mathrm{CP}$ as shown in example (18) below. 
(18)

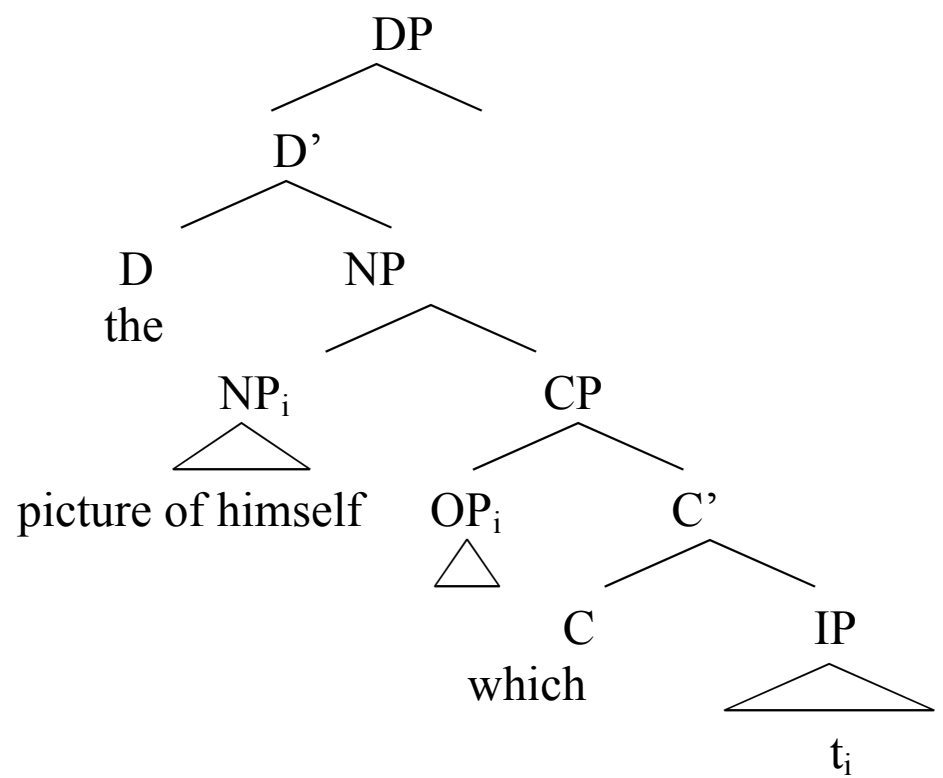

I begin by discussing Demuth and Harford's (1999) analysis of Bantu languages showing how this analysis falls short in capturing Ikalanga relatives.

4.1 Demuth and Harford's analysis (1999). The crux of Demuth and Harford's (1999) (henceforth D\&H) analysis of Bantu relatives is the idea that Bantu matrix clauses are IPs, and not CPs. They maintain that when the relative marker is a subminimal prosodic unit, it raises to $\mathrm{C}$, leaving the subject in spec IP. The raising of the verb to $\mathrm{C}$ results in subject-verb inversion. On the other hand, if the relative marker is a phonological word, then verb raising from I to $\mathrm{C}$ resulting in subject-verb inversion is blocked because the relative marker/pronoun occupies $\mathrm{C}$, and therefore the verb cannot move into an already occupied position. Using the Ikalanga sentence Nlume wa-ba-ka-bona boNeo $w a-e n d a$ 'The man who Neo and others saw has left' to illustrate, if we adopted D\&H's (1999) analysis, then the resulting structure of the Ikalanga relative is (19). 
(19)

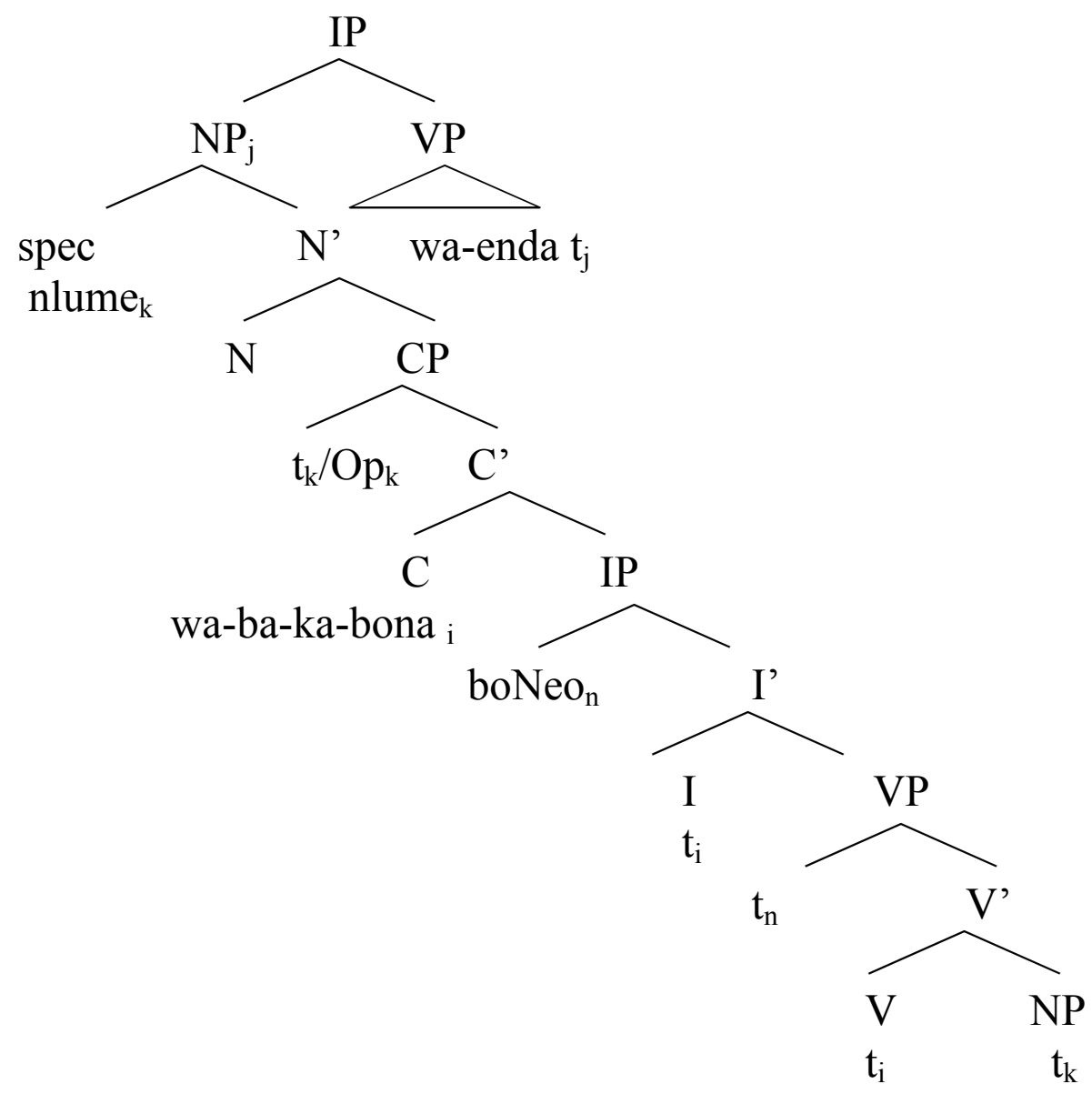

Recall that the relative marker in Ikalanga is a subminimal prosodic unit and not a phonological word. Thus following D\&H's (1999) analysis, we predict that there should be subject verb inversion in Ikalanga relatives as illustrated in example (19). However, this prediction is not borne out. The derived sentence using D\&H's analysis is (20):
(20)
$\begin{array}{lll}\text { nlúme } & \text { wa-bá-ká-bóna } & \text { boNéo } \\ \text { man1 } & \text { Rel.AGR1-SA2-past-see } & \text { Neo.and.others }\end{array}$
'the man who Neo and others saw'

Example (20) is not the canonical Ikalanga relative clause since in Ikalanga there is no subject verb inversion. This means that D\&H's (1999) analysis of Bantu relative clauses fails to account for the Ikalanga relative clause, although it nicely accounts for the Sotho and Shona relative clause. One might argue that perhaps the subject of the relative clause boNeo moves to spec-CP, giving us the correct Ikalanga grammatical word order. However, movement of the subject NP to spec-CP would be illicit because spec-CP is occupied by the trace of the relativized NP nlume (or Op, depending on the analysis). Due to the limitations 
of D\&H's analysis discussed here, I do not adopt this analysis as a tool for analyzing Ikalanga relatives. I explore other alternative analyses below.

4.2 Analysis No. 2. In this analysis I assume with others (D\&H 1999, Harford and Demuth, 1999, Zeller, 2004, Ngonyani, 2001, 2002, Buell, 2005, Letsholo, forthcoming) that finite verbs in Bantu move out of VP to T to check the Tense feature and that the morphological shape of the agreement morpheme on the verb is determined by the noun involved (Pak, ms). In addition, I assume that the relationship between such a noun and the verb is attained via grammatical agreement between the head noun and the verb through a spec-head agreement relation. Further, I assume that the verb comes into the lexicon inflected with all its morphology. With these assumptions in mind, let us now turn to the Ikalanga data below. Consider example (21):

(21)

Nlume boNéo wa-bá-ká-bóna wá-énda.

Man1 Neo2a Rel.AGR1-SA2-past-see SA1-leave

The man that [Neo and others] saw left.

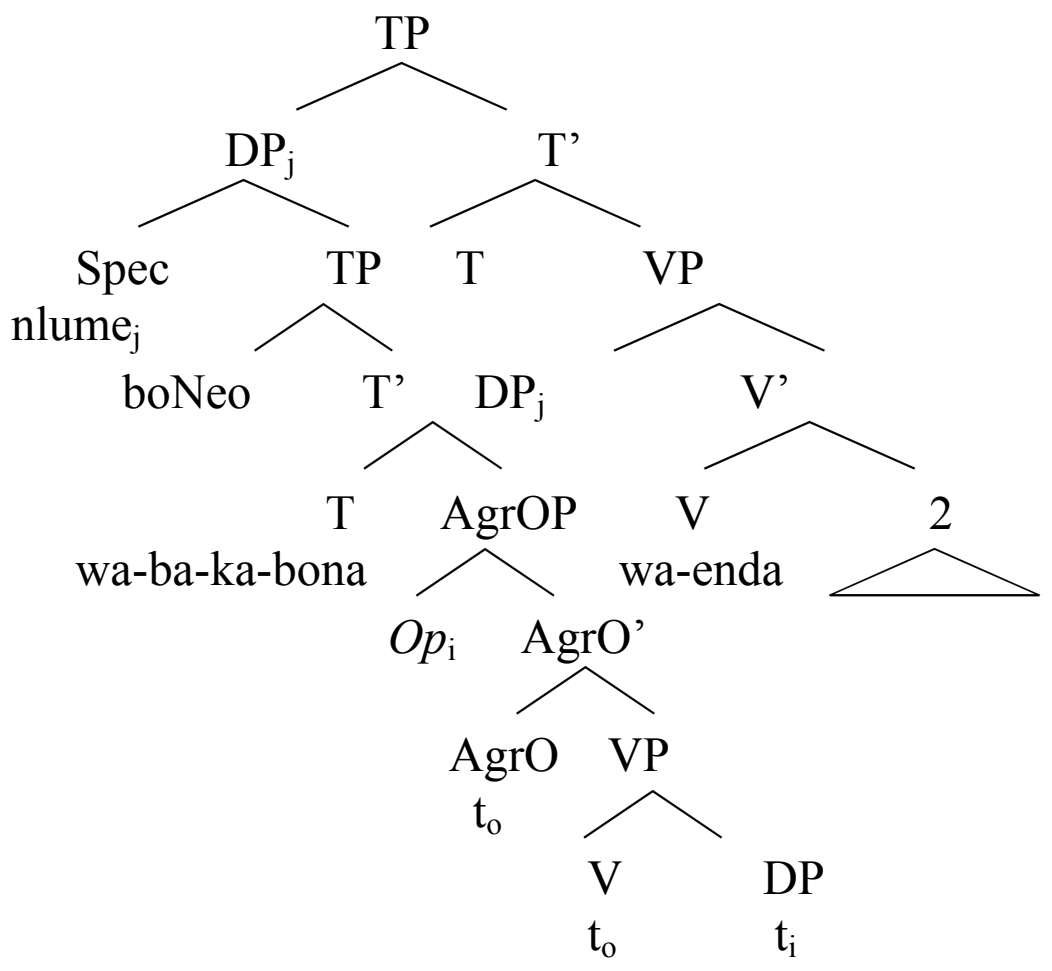

Sentence (22) above, according to our analysis is derived as follows: First, $\mathrm{V}$ moves to Agr to check its agr feature, then on to $\mathrm{T}$ to check tense. The operator moves to spec-AgrOP where a spec-head relation is established with the verb or its copy. The relativized NP is merged in spec-DP. This analysis is 
simple and straightforward. However, it does not account for how the relative feature of the relative marker cliticized to the verb checks the relative feature without $\mathrm{V}$ moving to the left periphery. Thus it is not clear at all how such a structure can even be distinguished from a simple declarative clause. Due to this shortcoming, I reject this analysis and consider a third analysis below.

1.1 Analysis No. 3. The third analysis I wish to explore here makes use of Rizzi's (1997) expanded CP analysis where CP breaks down into projections such as Topic Phrase (which is recursive) and Focus Phrase. The same assumptions discussed in analysis no. 2 above hold here the only difference being that while in analysis 2 the relative clause structure is analyzed as a TP, in this analysis it is analyzed as a CP. The resulting derivation in this analysis is (23).

(23)

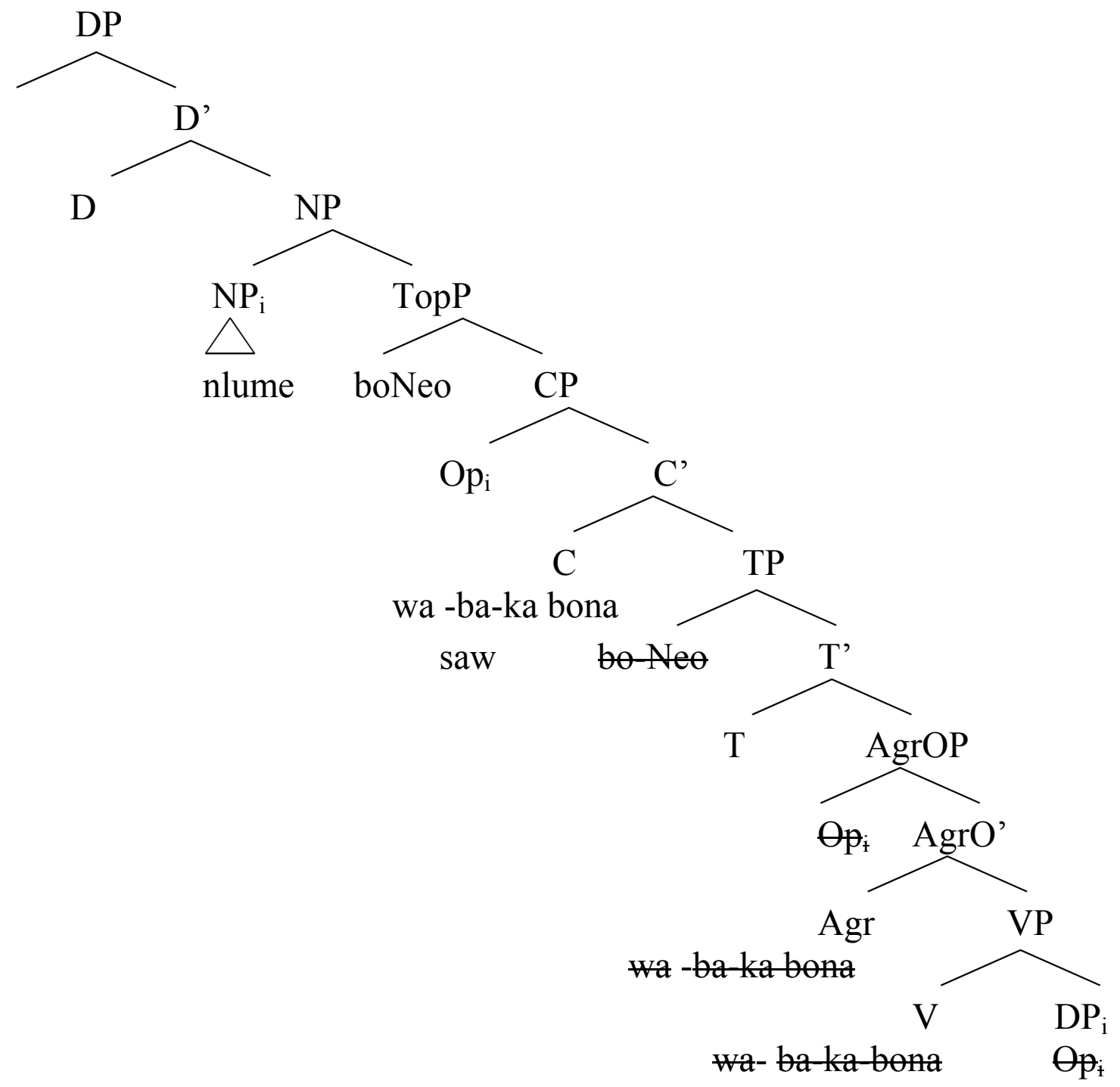


In this analysis, $\mathrm{V}$ first moves to Agr to check its Agr feature, then on to $\mathrm{T}$ to check tense and finally to the complementizer layer, that is, to $\mathrm{C}$, to check its relative feature. The operator (Op) moves to spec-AgrOP where a spec-head relation is established with the verb or its copy. The operator moves further to spec-CP to check its relative feature. The head noun nlume which shares features with the operator (and is co-indexed with it) is merged in spec DP. The subject NP of the relative clause, boNeo raises from spec VP to spec TP to check its $\mathrm{T}$ features, and I propose that it has a topic feature which makes it move further to spec-TopP to check the topic feature. This analysis has the advantage that it makes it clear how the relative clause construction checks its relative feature. However, the issue of word order particularly relating to the order of the relativized NP and the subject is problematic because it requires stipulating that the subject in relative clauses has a topic feature which forces it to move to some topic projection. More problematic with the $\mathrm{CP}$ analysis is the fact that no material that usually resides in $\mathrm{CP}$, e.g., adverbs, can intervene between the relativized object NP nlume and the subject NP boNeo. As illustrated in example (24), adverbs cannot intervene between the relativized NP and the subject of the relative clause. Consider the example below:

*Foúni pangwe mbísána ya-á-ká-súmbíka $\quad$ yá-ká-túra.
phone ${ }_{9}$ perhaps boy ${ }_{1}$ Rel.AGR9-SA A $_{1}$-past-hide SA9-past-expensive $_{9}$
'The cell phone that (perhaps) the boy hid is expensive.'

That none of the informants find this sentence acceptable suggests that no CP-related material is allowed to intervene between the relativized NP and the subject NP. This leads to the conclusion that although we have seen evidence that Ikalanga relatives display left periphery characteristics, they are not really $\mathrm{CP}$ structures. What then is the structure of the Ikalanga relative? I explore one more analysis below.

4.4 Analysis No. 4. In this analysis, I propose that the Ikalanga relative clause, although a left periphery structure, is not a $\mathrm{CP}$ but rather a structure that exists lower than the CP projection itself. A similar proposal was made in Pak (ms) regarding Luganda relatives. I make the same assumptions as those in analysis no. 3, the only difference being that here I do not assume that the relative clause in Ikalanga is a CP but a sub-CP projection. This is consonant with Rizzi's (1997) proposal that the left periphery consists of much finer structures than just CP. In addition, consonant with Ndayiregije (1999) and Sabel \& Zeller (2006) who propose that there is a FocP layer below TP which selects VP as its complement, I propose that in Ikalanga relatives, there is a projection RelP 
lower than TP, which selects VP as its complement. I propose (25) as the derivation of the Ikalanga relative.

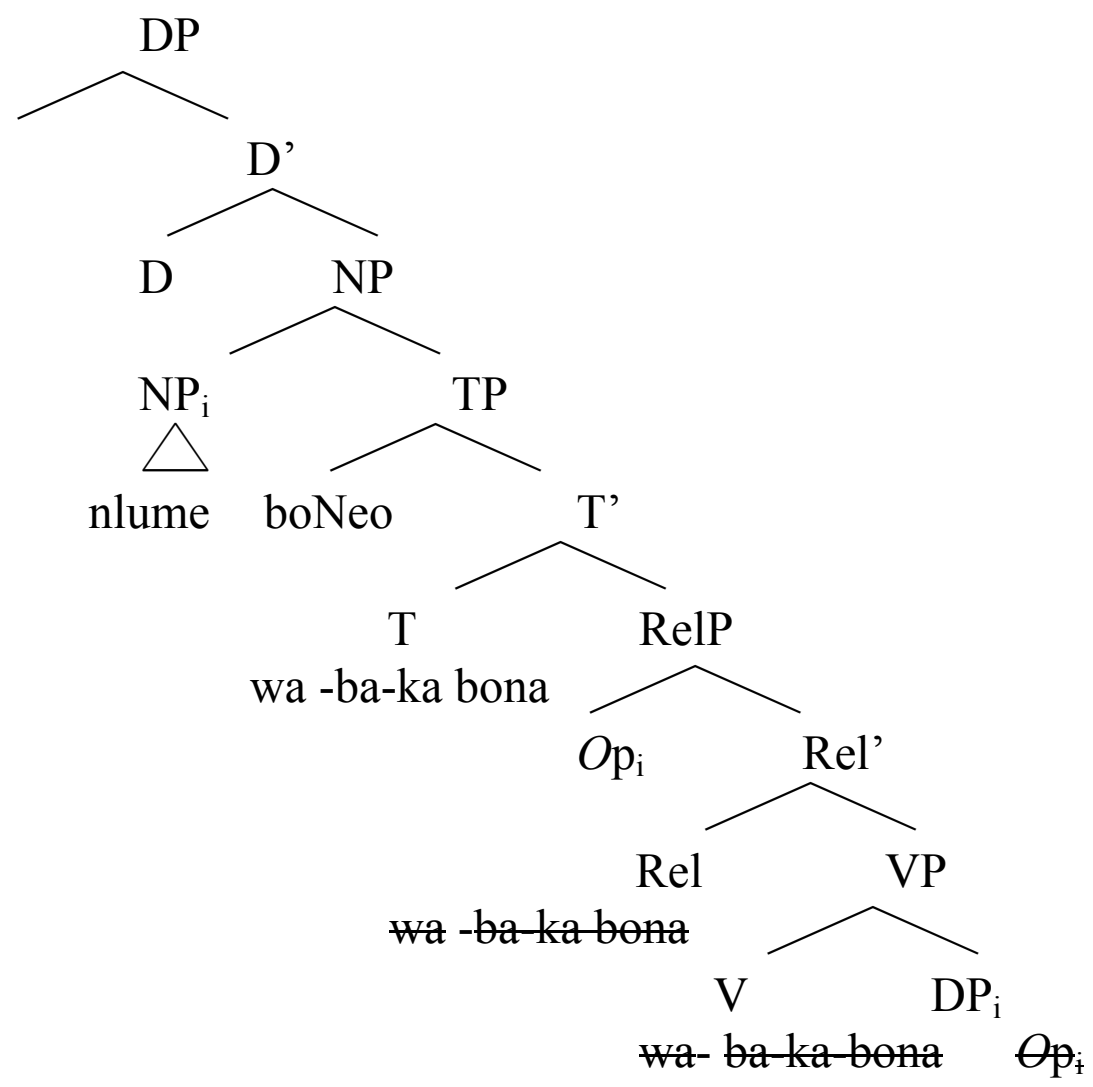

According to (25), the verb wa-ba-ka bona merges with the operator Op. The verb then moves to $\mathrm{T}$ where it checks its Agr and tense features and ultimately to Rel to check the relative feature. Similarly, the operator moves to Spec-Rel where its relative feature is checked against the verb which also has a relative feature. In this analysis, there is no CP layer above TP and therefore the problem of subject-verb inversion, which is problematic for the Ikalanga data in D\&H's (1999) analysis, does not arise. This analysis is simple and straightforward and alleviates not only the problem of subject-verb inversion encountered in D\&H's (1999) analysis but also the problem of stipulating that the subject NP has a topic feature in Ikalanga relatives. I therefore adopt analysis no. 4 as the best analysis for the Ikalanga data. The question then is Can this analysis be applied to other Bantu languages successfully? Let us take a few example languages and subject them to this analysis. 


\section{Relatives in other Bantu languages and how they differ from Ikalanga}

The analysis proposed above can equally successfully be applied to other Bantu languages if we analyze the languages from the perspective of whether they have subject inversion or not in relative clauses and also adopt all the assumptions discussed under analysis no. 2, which hold for Bantu languages. However, I posit that there is a parametric variation in Bantu languages in whether the Rel projection occurs within TP or above TP. In languages like Ikalanga and Luganda, RelP occurs below TP. In languages like Shona, Sesotho, Tsonga, Venda, the RelP (or CP if there is evidence of the existence of a $\mathrm{CP}$ in relatives in these languages) occurs above TP. Taking the following examples from Shona, Sesotho, Swati and Luganda respectively to illustrate how this analysis would work, beginning with the Shona example (26), their derivations proceed as follows:

\section{Shona}

$\begin{array}{llll}\text { Mbatya } & \text { dza-va-kason-era } & \text { vakadzi } & \text { mwenga } \\ \text { Clothes10 } & \text { RL10-SA2-sewed-APL } & \text { women2 } & \text { bride1 }\end{array}$

'clothes which the women sewed for the bride' (Demuth and Harford 1999)

[DP[NP mbatya ${ }_{i}\left[\mathrm{RelP} / \mathrm{CP} O \mathrm{p}_{\mathrm{i}}\left[\mathrm{Rel}\right.\right.$ dza-ba-ka-sonera ${ }_{\mathrm{j}}$ [TP[VP vakadzi[V $\mathrm{t}_{\mathrm{i}} \mathrm{t}_{\mathrm{j}}$ [NP mwenga]]]]]]]

\section{Sesotho}

\begin{tabular}{|c|c|c|}
\hline $\begin{array}{l}\text { Setulo } \\
\text { chair }\end{array}$ & $\begin{array}{l}\text { Seo } \\
\text { REL7 }\end{array}$ & $\begin{array}{l}\text { basadi } \\
\text { women2 }\end{array}$ \\
\hline
\end{tabular}

'the chair which the women bought today' (Demuth 1995)

[DP [NP setulo ${ }_{i}\left[\mathrm{RelP} / \mathrm{CP} O \mathrm{p}_{\mathrm{i}}\left[\mathrm{Rel} / \mathrm{C}\right.\right.$ seo [TP basadi ${ }_{\mathrm{k}}\left[\mathrm{T}\right.$ ba-se-rekileng ${ }_{\mathrm{j}}$ $\left.\left.\left.\left.\left.\left.\left[\mathrm{VP} \mathrm{t}_{\mathrm{k}} \mathrm{t}_{\mathrm{j}} \mathrm{t}_{\mathrm{i}}\right]\right]\right]\right]\right]\right]\right]$

\footnotetext{
(28) umfati tintfombileti-m-elekelela-ko woman1 girl10 RC10-OC1-help-RS

'the woman whom the girls help' ( Zeller, 2004: Ex 22)

[DP [NP umfatii $i_{i}\left[\mathrm{TP}\right.$ tintfombi ${ }_{k}\left[\mathrm{~T}\right.$ leti-m-elekelela-ko ${ }_{j}\left[\operatorname{RelP} O \mathrm{p}_{\mathrm{i}}\left[\operatorname{Rel} \mathrm{t}_{\mathrm{j}}\right.\right.$ $\left.\left.\left.\left.\left.\left.\left[\mathrm{VP} \mathrm{t}_{\mathrm{k}} \mathrm{t}_{\mathrm{j}} \mathrm{t}_{\mathrm{i}}\right]\right]\right]\right]\right]\right]\right]$
} 


\section{Luganda \\ (29) emikeeka mat4 girl2 rel4-SA2-past-plait neg-be4.of.use \\ 'The mats the girls plaited are unsuitable.' (Ashton et.al 1954:144) \\ [DP [NP emikeeka ${ }_{i}\left[\right.$ TP abalwa ${ }_{k}\left[T\right.$ gye-ba-a-luka ${ }_{j}\left[R e l P O p_{i}\left[R e l t_{j}[V P\right.\right.$ $\left.\left.\left.\left.\left.\left.\left.\mathrm{t}_{\mathrm{k}} \mathrm{t}_{\mathrm{j}} \mathrm{t}_{\mathrm{i}}\right]\right]\right]\right]\right]\right]\right]$}

As can be seen from the derivations of the Shona, Sotho, Swati and Luganda sentences above, the analysis proposed here accounts for the derivations of relative clauses in these different languages if we recognize that there is a parametric difference in Bantu languages in terms of whether the relative projection in a given language projects below or higher than TP. Thus, while in Shona (unmarked relatives) and Sesotho RelP projects higher than TP the Swati object relative cited in this paper patterns with Ikalanga and Luganda relatives in that their RelP projects lower than TP. Similarly, the marked Shona object relative discussed in Demuth and Harford and illustrated below, also patterns with Ikalanga and Luganda.
mbatya vakadzi dza-va-kasonera
clothes10 women2 REL10-SA2-sewed.for
mwenga
'clothes which the women sewed for the bride'( Demuth \& Harford, 1999 Ex (i))

\section{Conclusion}

Using lack of co-occurrence of the relative marker with other left periphery occurring elements such as conditionals and island constraints tests as evidence, I have argued that the relative marker in Ikalanga relatives is located in the left periphery. I have further argued that although the relative marker displays left periphery characteristics, evidence from adverb placement suggests that the Ikalanga relative clause is not a $\mathrm{CP}$ structure as in English type languages. Consistent with what Pak (ms) has proposed for Luganda relative clauses, I have also proposed that the Ikalanga relative clause structure is a sub$\mathrm{CP}$ structure which can be accommodated if we analyze it in terms of Rizzi (1997)'s expanded CP analysis.

I proposed that the relative clause structure of Ikalanga (and Luganda) projects a RelP below TP where the relative feature of the relative clause is checked. Since RelP is below TP, the relative feature is checked below TP. The verb, which hosts the relative marker, checks this feature and moves to $\mathrm{T}$ to check tense and agreement features there. The subject of the relative clause 
moves to spec-TP, its final landing place, just like in any other sentence. This accounts for the lack of subject verb inversion (predicted in D\&H's (1999) analysis) in Ikalanga although its relative marker is a unit that prosodically cliticizes to the verb. The relativized NP is merged in spec-DP of the relative clause phrase.

I have proposed that the structural differences between Ikalanga/Luganda relatives and other Bantu languages such as Shona and Sesotho can be accounted for if we recognize that there is a parameter in Bantu relatives regarding where the projection that checks the relative feature in these languages projects: it can project lower than $\mathrm{TP}$, for example in Ikalanga, Luganda, and Shona marked relatives (i.e., in languages that have no subject-verb inversion in relative clauses) or it can project higher than TP e.g. in Shona (unmarked) and Sesotho (i.e., languages that have subject-verb inversion in relative clauses). I also note that Shona seems to employ both strategies, i.e. RelP can project lower than IP or higher depending on stylistic preference. 


\section{Acknowledgements}

I have benefitted from support from the British Academy UK-Africa Academic Partnership Fund over the last three years, for which I am sincerely grateful.

\section{Abbreviations used}

\begin{tabular}{|l|l|l|l|}
\hline Agr & agreement & Op & operator \\
\hline Apl & applicative & Prg & progressive \\
\hline Cond & conditional & Rel & relative marker \\
\hline IMP & Imperfective & RelP & Relative projection \\
\hline $\mathrm{N}_{1,2,3}$ & number of the class to which a noun belongs & SA & subject agreement marker \\
\hline $\mathrm{Neg}$ & negation & Rs & Relative Suffix \\
\hline $\mathrm{OM}$ & object marker & & \\
\hline
\end{tabular}

\section{References}

Ashton, E.O., E.M.K. Mulira, E.G.M. Ndawula \& A.N. Tucker. 1954. A Luganda Grammar. London: Longmans, Green and Co.

Bokamba, Eyamba. G. 1976. Question formation in some Bantu languages.

$\mathrm{Ph} . \mathrm{D}$. dissertation, Indiana University.

Bresnan, Joan \& Sam Mchombo. 1987. Topic, pronoun, and agreement in Chichewa. Language 63, 741-782.

Buell, Leston. 2005. Issues in Zulu morphosyntax. Ph.D. dissertation, University of California, Los Angeles.

Chomsky, Noam. 2000. Minimalist Inquiries. The Framework. In Step by Steps: Essays on Minimalist Syntax in Honor of Howard Lasnik. ed. Martin, Roger, David Michaels \& Juan Uriagereka (eds.). Cambridge, MA: MIT Press: 89155.

Chomsky, Noam. 1977. On Wh-Movement. In Culicover, Peter, Thomas Wasow \& Adrian Akmajian (eds.). Formal Syntax. New York: Academic Press, pp. 71-132. 
Demuth, Katherine \& Harford, Carolyn. 1999. Verb raising and subject inversion in Bantu relatives. Journal of African Languages and Linguistics $20,1,41-61$.

Demuth, Katherine. 1995. Questions, Relatives, and Minimal Projection. In Language Acquisition, 4(1\&2), 49-71.

Guthrie, Malcom. 1967-71. Comparative Bantu. Volumes 1-4. Farnborough Heights: Gregg International Publishers.

Harford, Carolyn \& Demuth, Katherine. (1999). Prosody outranks syntax: An optimality approach to subject-verb inversion in Bantu relatives. Linguistic Analysis 29, 1-2, 47-68.

Henderson, Brent. 2007. The syntax of agreement in Bantu relatives. In Frederick Hoyt, Nikki Seifert, Alexandra Teodorescu \& Jessica White (eds.), Texas Linguistics Society 9: Morphosyntax of Underrepresented Languages:167-184.

Henderson, Brent. 2006. Multiple agreement, concord and case checking in Bantu. In Olaoba F. Arasanyi \& Michael Pemberton (eds.), Selected Proceedings of the $36^{\text {th }}$ Annual Conference on African Linguistics. Cascadilla Proceedings Project: 60-65.

Jelinek, Eloise. 1984. Empty categories, case and configurationality. Natural Language and Linguistic Theory 2, 39-76.

Kiss, Katalin. 1995. Discourse Configurational Languages, Oxford University Press, New York.

Kinyalolo, Kisangati. 1991. Syntactic dependencies and the spec-head agreement hypothesis in Kilega. Ph.D. dissertation, UCLA, Los Angeles.

Letsholo, Rose (forthcoming) The syntactic distribution of argument and adjunct WH constructions in Ikalanga, Journal of African Languages and Linguistics.

Letsholo, Rose. 2004. The role of tone and morphology in the syntax of the Ikalanga DP. In Southern African Linguistics and Applied Language Studies 24(3), 291-309. 
Letsholo, Rose. (2002). Syntactic domains in Ikalanga. Ph.D. dissertation, University of Michigan, Ann Arbor.

Mathangwane, Joyce. 1999. Ikalanga phonetics and phonology: A synchronic and diachronic study. Stanford: CSLI Publications.

Meeussen, A.E. 1971. Relative clauses in Bantu. Studies in African Linguistics. Supplement 2, 3-10.

Ndayiragije, Juvenile. 1999. Checking economy. Linguistic Inquiry 30, 3: 399444.

Ngonyani, Deogratias. 1999. XO movement in Kiswahili relative clause verbs. Linguistic Analysis 29: 1-2, 137-159.

Ngonyani, Deogratias. 2001. Evidence for head raising in Kiswahili relative clauses. Studies in African Linguistics 30, 1, 59-73.

Ngonyani, Deogratias. 2002. Sentential negation and verb movement in Bantu languages, Proceedings of BLS 28, 201-212.

Pak, Majorie. Relative clauses without CPs in Luganda (ms). University of Pennsylvania.

Rizzi, Luigi. 1997. The fine structure of the left periphery. In Haegeman, L. (ed.), Elements of Grammar, Dordrecht: Kluwer: 281-338.

Rizzi, Luigi. 1990. Relativized Minimality. Cambridge, Mass: MIT Press.

Sabel, Joachim \& Zeller, Jochen. 2006. WH question formation in Nguni. In Mugane, John, John P. Hutchison, Dee Worman (eds.), Selected Proceedings of the $35^{\text {th }}$ Annual Conference on African Linguistics: African Languages and Linguistics in Broad Perspective: 271-283.

Simango, Ron. S. 2007. Verb agreement and the syntax of CinSenga relative clauses. In Southern African Linguistics and Applied Language Studies 24(3), 277-290. 
Zeller, Jochen. 2004. Relative clause formation in the Bantu languages of South Africa. In Southern African Linguistics and Applied Language Studies 2004, 22 (1\&2), 75-93.

Zwart, Jan,W. 1997. A short note on relative constructions in Lega and Swahili. (ms). University of Groningen.

Department of English, University of Botswana, Private Bag 00703, Gaborone, Botswana

Letsholor@mopipi.ub.bw
Submitted: January 13, 2010

Accepted: March 24, 2010

Revisions received: June 5, 2010 